\title{
Risk of stomach cancer associated with 12 workplace hazards: analysis of death certificates from 24 states of the United States with the aid of job exposure matrices
}

\author{
Pierluigi Cocco, Mary H Ward, Mustafa Dosemeci
}

\begin{abstract}
Objective-To investigate the risk of gastric cancer associated with 12 workplace exposures suspected or discussed as aetiological agents in previous reports.

Methods-A case-control study was conducted based on the death certificates of several million deaths in 24 states of the United States in 1984-96. Overall, the data base included 41957 deaths from stomach cancer among subjects aged $\geqslant 25$ years. These were 20878 white men, 14125 white women, 4215 African American men, and 2739 African American women. Two controls for each case were selected from among subjects who died from nonmalignant diseases, frequency matched to cases by geographic region, race, sex and 5 year age group. Each three digit occupation and industry code listed in the $\mathbf{1 9 8 0}$ United States census was classified for probability and intensity of exposure to asbestos, inorganic dust, metals, lead, polycyclic aromatic hydrocarbons (PAHs), nitrogen oxides, nitrosamines, sulphuric acid, fertilisers, herbicides, other pesticides (including insecticides and fungicides), and wood dust. These job exposure matrices were subsequently applied to the occupation-industry combinations in the death certificates of study subjects, separately by sex and race.
\end{abstract}

Results-Risk of stomach cancer showed a modest association with occupational exposure to inorganic dust (odds ratio $(O R)=1.06 ; 95 \%$ confidence interval $(95 \%$ CI) 1.03 to 1.11 ) with significant increasing trends by probability and intensity of exposure overall and by cross classification of the two exposure metrices. Workplace exposure to nitrosamines also showed a modest association ( $O R=1.06$; $95 \%$ CI 1.01 to 1.11 ), but the excess risk was even smaller after adjusting for inorganic dust exposure. Risk of gastric cancer was not associated with any of the other workplace exposures considered in this study.

Conclusions-Non-differential misclassification of exposure may have caused negative findings in this study, and inorganic dust may be a partial surrogate for exposure to other unknown risk factors. Alternatively, our results suggest that occupational factors contribute little to the aetiology of gastric cancer. Inorganic dust might act through non-specific mechanisms, similar to those proposed for salt, aspirin, and heat by other authors.

(Occup Environ Med 1999;56:781-787)

Keywords: stomach; neoplasms; occupational exposure

In a review of occupational risk factors for stomach cancer we suggested that various occupational exposures may cause or contribute to gastric carcinogenesis. ${ }^{1}$ Ionising radiation and $\mathrm{N}$-nitroso compounds, either directly or through the formation of free radicals or nucleophilic intermediates, may damage the DNA of the cells of the gastric mucosa, acting as initiators of the carcinogenic process. Other physical agents, such as asbestos and other inorganic dusts, could be irritants to the gastric mucosa and act as cocarcinogens in a way similar to the mechanism proposed for salt, aspirin, and heat. $^{2}{ }^{3}$ These agents cause a superficial gastritis and may increase cell proliferation, thus promoting initiated clones. Dust could also act as a carrier delivering carcinogens to the gastric mucosa. The effectiveness of this mechanism has been experimentally proved in lung carcinogenesis. ${ }^{4}$

A major cause of concern is that most studies of gastric cancer and occupation rely on poor environmental data. Often, only occupational titles are available to imply exposure to suspected gastric carcinogens. Even surrogates for exposure-such as duration of employment-are seldom used to calculate dose-response trends. Besides, small study size has been a limiting factor in interpreting findings. In the absence of industrial hygiene measurements, use of job exposure matrices, which has provided a useful tool in other studies, ${ }^{5}$ might be profitable. To test the hypothesis of a role of occupational risk factors in the aetiology of gastric cancer, we established job exposure matrices for 12 suspected gastric carcinogens in the workplace and applied them to the occupation-industry combinations in a large data base including death certificates from 24 states from the United States in 1984-96. Poor detail of the occupational information is still a concern in this study, but both the large size of the study population and the use of already designed job exposure matrices are new contributions. 
Methods

Since 1984, the National Cancer Institute, the National Institute for Occupational Safety and Health, and the National Center for Health Statistics have supported the coding of occupation and industry titles on death certificates from 24 states from the United States according to the 1980 United States census occupation and industry codes. ${ }^{6}$ Details on the data base of death certificates from 24 states of the United States have been reported elsewhere. ${ }^{7}$ We extracted data of 41957 subjects who died from stomach cancer at age $\geqslant 25$ from several million death certificates in 1984-96. These were 20878 white men, 14125 white women, 4215 African American men, and 2739 African American women. We used a case-control design to evaluate the association of risk of stomach cancer with 12 workplace exposures, separately by sex and race. Two controls for each case were selected from among subjects who died from non-malignant diseases, frequency matched to cases by geographic region, race, sex, and 5 year age group.

One occupation and industry is reported on the death certificate. Information on duration or other characteristics of employment is not available. By applying job exposure matrices to the occupation-industry combinations in the death certificates of study subjects, we evaluated occupational exposure to 12 workplace hazards, that we previously discussed in a review on occupational risk factors for stomach cancer ${ }^{1}$ - namely asbestos, inorganic dust, metals, lead, polycyclic aromatic hydrocarbons (PAHs), nitrogen oxides, nitrosamines, sulphuric acid, fertilisers, herbicides, other pesticides (including insecticides and fungicides), and wood dust. An estimate of intensity (none $=0$, low $=1$, medium $=2$, high $=3$ ) and probability (none $=0$, low $=1$, medium $=2$, high $=3$ ) of exposure to each of the 12 occupational hazards was developed by two authors (MD and PC) for each three digit 1980 United States census occupation and industry code. Intensity of exposure was estimated based upon industrial hygiene and occupational health textbooks, ${ }^{89}$ computerised exposure data bases (OSHA files, NIOSH inspections data base), unpublished industrial hygiene reports, and personal experience. The probability index was estimated based on the proportion of exposed

Table 1 Risks of stomach cancer by probability of exposure to suspected gastric carcinogens, by sex and race

\begin{tabular}{|c|c|c|c|c|c|c|c|c|}
\hline \multirow[b]{2}{*}{ Exposure } & \multirow[b]{2}{*}{ Study group } & \multirow{2}{*}{$\begin{array}{l}\text { Unexposed } \\
(O R=1) \\
(n)\end{array}$} & \multicolumn{6}{|c|}{ Probability of exposure ( $n$ OR $(95 \% C I)$ ) } \\
\hline & & & Low & & Medium & & High & \\
\hline \multirow[t]{4}{*}{ Asbestos† } & WM & 16859 & & & 4007 & $0.97(0.93$ to 1.02$)$ & 22 & $1.09(0.54$ to 2.20$)$ \\
\hline & AAM & 2856 & & & 1357 & $1.08(0.99$ to 1.17$)$ & 2 & 0.78 (0.15 to 4.03$)$ \\
\hline & WW & 13356 & & & 769 & $1.06(0.96$ to 1.17$)$ & 0 & -- \\
\hline & AAW & 2538 & & & 201 & $1.19(0.98$ to 1.45$)$ & 0 & -- \\
\hline \multirow[t]{4}{*}{ Inorganic dust } & $\mathrm{WM}^{\star \star}$ & 11974 & 1361 & $0.98(0.92$ to 1.05$)$ & 2666 & $1.11(1.05$ to 1.17$)$ & 4877 & $1.08(1.03$ to 1.13$)$ \\
\hline & $\mathrm{AAM}^{\star}$ & 1990 & 274 & $1.16(0.99$ to 1.36$)$ & 825 & $1.19(1.07$ to 1.32$)$ & 1126 & $1.08(0.98$ to 1.20$)$ \\
\hline & $\mathrm{WW}^{\star \star}$ & 13482 & 175 & $1.17(0.96$ to 1.41$)$ & 337 & $1.22(1.06$ to 1.41$)$ & 131 & 1.37 (1.10 to 1.72$)$ \\
\hline & AAW & 2558 & 28 & $1.12(0.70$ to 1.79$)$ & 71 & $0.90(0.67$ to 1.20$)$ & 82 & $1.16(0.87$ to 1.55$)$ \\
\hline \multirow{4}{*}{ Metals } & WM & 16572 & 662 & $1.05(0.96$ to 1.16$)$ & 2142 & $1.04(0.98$ to 1.10$)$ & 1502 & $1.06(0.99$ to 1.13$)$ \\
\hline & AAM & 3473 & 120 & $1.08(0.86$ to 1.35$)$ & 448 & $1.01(0.90$ to 1.14$)$ & 174 & $1.08(0.89$ to 1.31$)$ \\
\hline & WW & 13696 & 67 & $0.86(0.65$ to 1.15$)$ & 292 & $1.22(1.05$ to 1.41$)$ & 70 & $0.99(0.74$ to 1.32$)$ \\
\hline & AAW & 2678 & 9 & $1.41(0.60$ to 3.32$)$ & 46 & $1.14(0.79$ to 1.65$)$ & 6 & $0.95(0.35$ to 2.54$)$ \\
\hline \multirow[t]{4}{*}{ Lead } & WM & 17276 & 1572 & $1.0(0.94$ to 1.07$)$ & 527 & $1.01(0.91$ to 1.13$)$ & 1503 & $0.92(0.86$ to 0.99$)$ \\
\hline & AAM & 3365 & 312 & $1.04(0.90$ to 1.20$)$ & 85 & $0.93(0.72$ to 1.21$)$ & 453 & $1.15(1.01$ to 1.32$)$ \\
\hline & WW & 13753 & 224 & $1.01(0.86$ to 1.19$)$ & 83 & $0.90(0.69$ to 1.16$)$ & 65 & 1.53 (1.10 to 2.12$)$ \\
\hline & AAW & 2677 & 43 & $1.50(1.01$ to 2.24$)$ & 9 & $1.37(0.58$ to 3.21$)$ & 10 & $1.76(0.74$ to 4.16$)$ \\
\hline \multirow{4}{*}{$\begin{array}{l}\text { Polycyclic aromatic } \\
\text { hydrocarbons }\end{array}$} & WM & 14232 & 1356 & $1.04(0.97$ to 1.12$)$ & 1896 & $1.06(1.0$ to 1.13$)$ & 3394 & $0.99(0.95$ to 1.05$)$ \\
\hline & AAM & 2815 & 256 & $1.02(0.87$ to 1.20$)$ & 325 & $1.02(0.88$ to 1.17$)$ & 819 & $1.01(0.91$ to 1.11$)$ \\
\hline & $\mathrm{WW}^{\star \star}$ & 13736 & 201 & $1.16(0.97$ to 1.38$)$ & 90 & $1.13(0.87$ to 1.46$)$ & 98 & $1.57(1.20$ to 2.06$)$ \\
\hline & AAW & 2614 & 33 & $0.96(0.63$ to 1.46$)$ & 13 & $1.48(0.72$ to 3.02$)$ & 79 & $1.16(0.87$ to 1.56$)$ \\
\hline \multirow[t]{4}{*}{ Nitrosamines } & $W M^{\star \star}$ & 16478 & 792 & $1.01(0.93$ to 1.10$)$ & 2760 & $1.08(1.02$ to 1.14$)$ & 848 & $1.05(0.97$ to 1.15$)$ \\
\hline & AAM & 3322 & 163 & $0.84(0.70$ to 1.02$)$ & 567 & $0.97(0.86$ to 1.09$)$ & 163 & $1.09(0.89$ to 1.32$)$ \\
\hline & $\mathrm{WW}^{\star \star}$ & 13810 & 176 & $1.09(0.91$ to 1.32$)$ & 123 & $1.40(1.11$ to 1.78$)$ & 16 & $1.42(0.74$ to 2.70$)$ \\
\hline & AAW & 2608 & 40 & $1.23(0.82$ to 1.83$)$ & 88 & $1.27(0.96$ to 1.69$)$ & 3 & $1.47(0.33$ to 6.59$)$ \\
\hline \multirow[t]{4}{*}{ Nitrogen oxides } & WM & 14794 & 788 & $1.04(0.95$ to 1.14$)$ & 669 & 0.98 (0.89 to 1.08$)$ & 4627 & $1.0(0.96$ to 1.05$)$ \\
\hline & AAM & 2835 & 216 & $0.99(0.84$ to 1.18$)$ & 219 & $0.98(0.83$ to 1.16$)$ & 945 & $1.03(0.93$ to 1.13$)$ \\
\hline & $\mathrm{WW}^{\star \star}$ & 13815 & 147 & $1.20(0.97$ to 1.48$)$ & 38 & 1.35 (0.89 to 2.04$)$ & 125 & 1.41 (1.12 to 1.78$)$ \\
\hline & AAW & 2612 & 37 & $1.49(0.97$ to 2.29$)$ & 8 & $1.48(0.59$ to 3.70$)$ & 82 & $1.17(0.88$ to 1.56$)$ \\
\hline \multirow[t]{4}{*}{ Sulphuric acid } & WM & 15228 & 4531 & $1.0(0.96$ to 1.04$)$ & 675 & $1.12(1.01$ to 1.23$)$ & 444 & $0.96(0.85$ to 1.08$)$ \\
\hline & AAM & 2678 & 1212 & $1.02(0.94$ to 1.12$)$ & 223 & $1.12(0.94$ to 1.33$)$ & 102 & $1.16(0.90$ to 1.50$)$ \\
\hline & Ww & 13128 & 675 & $0.91(0.83$ to 1.0$)$ & 310 & $1.02(0.87$ to 1.20$)$ & 12 & $0.87(0.44$ to 1.72$)$ \\
\hline & AAW & 2103 & 219 & $1.06(0.88$ to 1.28$)$ & 416 & $0.96(0.79$ to 1.17$)$ & 1 & 2.07 ( 0.13 to 33.3$)$ \\
\hline \multirow[t]{4}{*}{ Herbicides } & WM & 19190 & 146 & $1.12(0.91$ to 1.37$)$ & 19 & $0.91(0.53$ to 1.55$)$ & 1523 & $1.06(0.98$ to 1.15$)$ \\
\hline & AAM & 3817 & 62 & $1.13(0.82$ to 1.55$)$ & 10 & 0.68 (0.33 to 1.40$)$ & 326 & $0.91(0.78$ to 1.06$)$ \\
\hline & WW & 14062 & 5 & 2.05 (0.59 to 7.08$)$ & 4 & $2.10(0.52$ to 8.41$)$ & 54 & $1.71(1.18$ to 2.46$)$ \\
\hline & AAW & 2688 & 1 & $0.64(0.07$ to 6.20$)$ & 0 & - - & 50 & $1.25(0.86$ to 1.80$)$ \\
\hline \multirow[t]{4}{*}{ Other pesticides } & WM & 18099 & 1104 & 0.99 (0.91 to 1.07$)$ & 121 & $1.05(0.84$ to 1.31$)$ & 1554 & $1.04(0.96$ to 1.12$)$ \\
\hline & AAM & 3318 & 508 & $1.17(1.03$ to 1.32$)$ & 58 & $0.95(0.69$ to 1.30$)$ & 331 & $0.94(0.80$ to 1.09$)$ \\
\hline & WW & 13930 & 110 & $1.41(1.10$ to 1.81$)$ & 23 & $0.87(0.53$ to 1.42$)$ & 62 & $1.78(1.26$ to 2.51$)$ \\
\hline & AAW & 2634 & 43 & $0.78(0.54$ to 1.12$)$ & 12 & $0.71(0.37$ to 1.37$)$ & 50 & $1.22(0.85$ to 1.77$)$ \\
\hline \multirow[t]{4}{*}{ Fertilisers } & WM & 19058 & 151 & $0.90(0.74$ to 1.09$)$ & 148 & $1.30(1.06$ to 1.60$)$ & 1521 & $1.06(0.98$ to 1.15$)$ \\
\hline & AAM & 3760 & 37 & $0.76(0.52$ to 1.12$)$ & 100 & $0.95(0.74$ to 1.22$)$ & 318 & $0.89(0.76$ to 1.03$)$ \\
\hline & WW & 14012 & 48 & $1.0(0.70$ to 1.41$)$ & 7 & $0.86(0.36$ to 2.08$)$ & 58 & $1.77(1.23$ to 2.53$)$ \\
\hline & AAW & 2648 & 16 & $1.28(0.68$ to 2.42$)$ & 25 & $0.97(0.59$ to 1.57$)$ & 50 & $1.27(0.88$ to 1.84$)$ \\
\hline \multirow[t]{4}{*}{ Wood dust } & WM & 19107 & 903 & $0.96(0.89$ to 1.05$)$ & 195 & 0.91 (0.77 to 1.08$)$ & 673 & $1.0(0.90$ to 1.10$)$ \\
\hline & AAM & 3523 & 482 & $1.17(1.03$ to 1.33$)$ & 80 & $0.96(0.73$ to 1.26$)$ & 130 & $0.93(0.75$ to 1.16$)$ \\
\hline & WW & 14022 & 75 & $0.91(0.69$ to 1.20$)$ & 22 & $0.71(0.44$ to 1.16$)$ & 6 & $0.84(0.32$ to 2.18$)$ \\
\hline & AAW & 2715 & 18 & $0.86(0.49$ to 1.50$)$ & 6 & $1.33(0.47$ to 3.76$)$ & 0 & -- \\
\hline
\end{tabular}

${ }^{\star} \mathrm{p}<0.05 ;{ }^{\star \star} \mathrm{p}<0.01$ test for trend.

†The reference group for subjects exposed to asbestos includes those with a low probability of exposure, due to the difficulty in estimating a baseline exposure.

WM=white men; AAM=African American men; WF=white women; AAW=African American women). 
workers within a given job title or industry, and the number of occupations or industries coded likewise. To obtain one intensity and one probability score for a given exposure in each study subject, intensity and probability scores associated with the occupation and the industry were considered in two ways: (a) if information on exposure resulted from the occupation regardless of industry - for example, plumber, or welder-we calculated the subject's intensity and probability scores as the square of the occupational score; $(b)$ if industry was the main contributor to exposure assessment-for example, truck driver in the rubber industry, or labourer in the construction industry-then the subject's probability and intensity scores resulted from multiplying the respective score attributed to the occupation code times that attributed to the industry code. The rationale for squaring or multiplying scores in semiquantitative retrospective exposure assessment has been described elsewhere. ${ }^{10}$ In the present study, the main scope of this strategy was to have individual scores in the same order of magnitude, whether deriving from occupation only or from occupation and industry. The final scores of probability and intensity of exposure were further categorised within four levels (none $=0, \quad$ low $=1-2, \quad$ medium $=3-4$, high $=6-9$ ).

Odds ratios (ORs) were estimated by logistic regression, and 95\% confidence intervals (95\% CIs) with the GMBO program in the Epicure software. Covariates included in the logistic regression model were age, ethnic origin (American, Hispanic, European, other, unknown), marital status (never married versus ever married), metropolitan versus non-metropolitan residence, and five categories of socioeconomic status based on Green's standardised score for specific occupations. ${ }^{11}$ Statistical significance of trends in risk by increasing exposure intensity and probability was tested by assuming covariates as noncategorical, and subtracting from the result of the goodness of fit statistic, obtained when the exposure variable was not included in the logistic regression model, the result of the same statistic with the exposure variable. Under the null hypothesis, this test has a $\chi^{2}$

Table 2 Risks of stomach cancer by intensity of exposure to suspected gastric carcinogens groups

\begin{tabular}{|c|c|c|c|c|c|c|c|c|}
\hline \multirow[b]{2}{*}{ Exposure } & \multirow[b]{2}{*}{ Study group } & \multirow{2}{*}{$\begin{array}{l}\text { Unexposed } \\
(O R=1)(n)\end{array}$} & \multicolumn{6}{|c|}{ Intensity of exposure (n OR $(95 \% \mathrm{CI})$ ) } \\
\hline & & & Low & & Mediun & & High & \\
\hline \multirow[t]{4}{*}{ Asbestost } & WM & 17783 & & & 2764 & $1.0(0.95$ to 1.04$)$ & 431 & $1.01(0.90$ to 1.14$)$ \\
\hline & AAM & 3271 & & & 848 & $1.10(1.0$ to 1.20$)$ & 96 & $0.97(0.76$ to 1.24$)$ \\
\hline & WW & 13912 & & & 213 & $1.07(0.90$ to 1.26$)$ & 0 & -- \\
\hline & AAW & 2686 & & & 51 & $1.23(0.86$ to 1.75$)$ & 2 & $3.90(0.35$ to 43.1$)$ \\
\hline \multirow[t]{4}{*}{ Inorganic dust } & $\mathrm{WM}^{\star \star \star}$ & 11974 & 4635 & $1.05(1.0$ to 1.10$)$ & 3002 & $1.07(1.01$ to 1.12$)$ & 1267 & $1.13(1.05$ to 1.21$)$ \\
\hline & AAM & 1990 & 1100 & $1.13(1.02$ to 1.24$)$ & 842 & $1.22(1.10$ to 1.36$)$ & 283 & $0.95(0.82$ to 1.11$)$ \\
\hline & WW & 13482 & 280 & $1.37(1.17$ to 1.60$)$ & 296 & $1.23(1.06$ to 1.42$)$ & 67 & $0.88(0.65$ to 1.17$)$ \\
\hline & AAW & 2558 & 125 & $0.98(0.78$ to 1.24$)$ & 36 & $1.04(0.69$ to 1.57$)$ & 20 & $1.47(0.82$ to 2.64$)$ \\
\hline \multirow[t]{4}{*}{ Metals } & $W M^{\star \star}$ & 16572 & 1256 & $1.02(0.95$ to 1.09$)$ & 1509 & $1.04(0.97$ to 1.11$)$ & 1541 & $1.09(1.02$ to 1.16$)$ \\
\hline & AAM & 3473 & 158 & $0.96(0.79$ to 1.17$)$ & 298 & $1.13(0.97$ to 1.31$)$ & 286 & $0.99(0.86$ to 1.15$)$ \\
\hline & $\mathrm{WW}^{\star}$ & 13696 & 50 & $0.94(0.67$ to 1.32$)$ & 242 & $1.14(0.97$ to 1.34$)$ & 137 & $1.10(0.89$ to 1.37$)$ \\
\hline & AAW & 2678 & 7 & $1.40(0.53$ to 3.68$)$ & 25 & $0.92(0.57$ to 1.49$)$ & 29 & $1.39(0.86$ to 2.25$)$ \\
\hline \multirow[t]{4}{*}{ Lead } & WM & 17276 & 2168 & $0.96(0.90$ to 1.02$)$ & 1144 & $0.96(0.89$ to 1.04$)$ & 290 & $1.10(0.95$ to 1.27$)$ \\
\hline & AAM & 3365 & 556 & $1.10(0.98$ to 1.25$)$ & 242 & $1.11(0.95$ to 1.31$)$ & 52 & $0.81(0.59$ to 1.13$)$ \\
\hline & WW & 13753 & 170 & $1.09(0.90$ to 1.31$)$ & 165 & $1.0(0.83$ to 1.21$)$ & 37 & $1.02(0.68$ to 1.51$)$ \\
\hline & AAW & 2677 & 24 & $1.82(1.04$ to 3.18$)$ & 35 & $1.39(0.90$ to 2.15$)$ & 3 & $1.25(0.30$ to 5.23$)$ \\
\hline \multirow{4}{*}{$\begin{array}{l}\text { Polycyclic aromatic } \\
\text { hydrocarbons }\end{array}$} & WM & 14232 & 4047 & $1.0(0.95$ to 1.04$)$ & 1983 & $1.08(1.02$ to 1.15$)$ & 616 & $1.0(0.90$ to 1.10$)$ \\
\hline & AAM & 2815 & 855 & $1.0(0.91$ to 1.10$)$ & 320 & $1.06(0.92$ to 1.23$)$ & 225 & $1.0(0.84$ to 1.18$)$ \\
\hline & WW & 13736 & 159 & $1.29(1.06$ to 1.59$)$ & 158 & $1.39(1.13$ to 1.70$)$ & 72 & $0.89(0.67$ to 1.18$)$ \\
\hline & AAW & 2614 & 85 & $1.11(0.84$ to 1.46$)$ & 21 & $1.06(0.63$ to 1.81$)$ & 19 & $1.32(0.73$ to 2.37$)$ \\
\hline \multirow[t]{4}{*}{ Nitrosamines } & $\mathrm{WM}^{\star}$ & 16478 & 433 & $0.99(0.88$ to 1.12$)$ & 3474 & $1.06(1.01$ to 1.11$)$ & 493 & $1.16(1.03$ to 1.30$)$ \\
\hline & AAM & 3322 & 48 & $1.26(0.87$ to 1.82$)$ & 666 & $0.95(0.85$ to 1.05$)$ & 179 & $0.96(0.79$ to 1.15$)$ \\
\hline & WW & 13810 & 17 & $1.29(0.70$ to 2.38$)$ & 230 & $1.19(1.0$ to 1.41$)$ & 68 & $1.27(0.93$ to 1.72$)$ \\
\hline & AAW & 2608 & 0 & -- & 121 & $1.30(1.02$ to 1.65$)$ & 10 & $1.48(0.66$ to 3.34$)$ \\
\hline \multirow[t]{4}{*}{ Nitrogen oxides } & WM & 14794 & 3636 & 0.99 (0.94 to 1.04$)$ & 1334 & $1.01(0.94$ to 1.08$)$ & 1114 & $1.05(0.97$ to 1.14$)$ \\
\hline & $\mathrm{AAM}$ & 2835 & 804 & $1.0(0.90$ to 1.10$)$ & 309 & $1.03(0.89$ to 1.19$)$ & 267 & $1.03(0.88$ to 1.20$)$ \\
\hline & WW & 13815 & 116 & $1.50(1.17$ to 1.91$)$ & 98 & $1.28(1.0$ to 1.66$)$ & 96 & $1.12(0.87$ to 1.45$)$ \\
\hline & $\mathrm{AAW}^{\star}$ & 2612 & 81 & $1.18(0.88$ to 1.57$)$ & 20 & $1.38(0.78$ to 2.44$)$ & 26 & $1.54(0.92$ to 2.59$)$ \\
\hline \multirow[t]{4}{*}{ Sulphuric acid } & $\mathrm{WM}^{\star \star}$ & 15228 & 4113 & $0.99(0.95$ to 1.03$)$ & 1274 & $1.03(0.96$ to 1.11$)$ & 263 & $1.23(1.05$ to 1.44$)$ \\
\hline & AAM & 2678 & 1232 & $1.04(0.96$ to 1.14$)$ & 228 & $1.05(0.89$ to 1.24$)$ & 77 & $1.11(0.83$ to 1.47$)$ \\
\hline & WW & 13128 & 565 & $0.88(0.79$ to 0.98$)$ & 419 & $1.04(0.91$ to 1.19$)$ & 13 & $0.78(0.41$ to 1.49$)$ \\
\hline & AAW & 2103 & 212 & $1.09(0.90$ to 1.32$)$ & 420 & $0.96(0.79$ to 1.16$)$ & 4 & 0.55 (0.18 to 1.68$)$ \\
\hline \multirow[t]{4}{*}{ Herbicides } & WM & 19190 & 22 & $1.11(0.65$ to 1.88$)$ & 92 & $1.17(0.90$ to 1.51$)$ & 1574 & $1.05(0.97$ to 1.14$)$ \\
\hline & AAM & 3817 & 4 & $1.07(0.32$ to 3.59$)$ & 17 & $0.88(0.50$ to 1.57$)$ & 377 & $0.93(0.81$ to 1.08$)$ \\
\hline & WW & 14062 & 2 & $4.09(0.37$ to 45.6$)$ & 8 & $3.26(1.07$ to 9.99$)$ & 53 & $1.60(1.11$ to 2.31$)$ \\
\hline & AAW & 2688 & 0 & -- & 1 & $0.61(0.06$ to 5.85$)$ & 50 & $1.24(0.86$ to 1.78$)$ \\
\hline \multirow[t]{4}{*}{ Other pesticides } & WM & 18099 & 652 & $1.14(1.02$ to 1.27$)$ & 537 & $0.85(0.77$ to 0.95$)$ & 1590 & $1.08(1.0$ to 1.18$)$ \\
\hline & AAM & 3318 & 356 & $1.16(1.0$ to 1.34$)$ & 160 & $1.14(0.93$ to 1.40$)$ & 381 & $0.95(0.82$ to 1.10$)$ \\
\hline & WW & 13930 & 102 & $1.40(1.08$ to 1.81$)$ & 33 & $1.22(0.79$ to 1.88$)$ & 60 & $1.51(1.08$ to 2.13$)$ \\
\hline & AAW & 2634 & 38 & $0.70(0.48$ to 1.02$)$ & 8 & $0.95(0.41$ to 2.20$)$ & 59 & $1.17(0.83$ to 1.64$)$ \\
\hline \multirow[t]{4}{*}{ Fertilisers } & WM & 19058 & 106 & $1.17(0.92$ to 1.48$)$ & 1529 & $1.04(0.96$ to 1.13$)$ & 185 & $1.13(0.94$ to 1.36$)$ \\
\hline & AAM & 3760 & 20 & $0.81(0.48$ to 1.36$)$ & 295 & $0.85(0.72$ to 0.99$)$ & 140 & $1.0(0.81$ to 1.24$)$ \\
\hline & WW & 14012 & 12 & $1.56(0.73$ to 3.34$)$ & 92 & $1.18(0.90$ to 1.54$)$ & 9 & $2.36(0.91$ to 6.15$)$ \\
\hline & AAW & 2648 & 1 & $0.60(0.06$ to 5.78$)$ & 63 & $1.23(0.89$ to 1.71$)$ & 27 & $1.09(0.67$ to 1.76$)$ \\
\hline \multirow[t]{4}{*}{ Wood dust } & WM & 19107 & 771 & 0.98 (0.89 to 1.07$)$ & 837 & $0.98(0.90$ to 1.07$)$ & 163 & $0.88(0.73$ to 1.06$)$ \\
\hline & AAM & 3523 & 406 & $1.16(1.02$ to 1.33$)$ & 206 & $1.10(0.93$ to 1.32$)$ & 80 & $0.80(0.61$ to 1.04$)$ \\
\hline & WW & 14022 & 23 & $0.83(0.51$ to 1.35$)$ & 72 & $0.89(0.67$ to 1.18$)$ & 8 & $0.69(0.31$ to 1.55$)$ \\
\hline & AAW & 2715 & 4 & $0.75(0.24$ to 2.36$)$ & 19 & $0.94(0.54$ to 1.63$)$ & 1 & $0.40(0.05$ to 3.42$)$ \\
\hline
\end{tabular}

${ }^{\star} \mathrm{p}<0.05 ;{ }^{\star \star} \mathrm{p}<0.01$ test for trend.

tThe reference group for subjects exposed to asbestos includes those with a low intensity of exposure, due to the difficulty in estimating a baseline exposure. The number of unexposed subjects differs between the two exposure metrics, as subjects may be attributed to different probabilities of intensity of exposure.

$\mathrm{WM}=$ white men; $\mathrm{AAM}=\mathrm{African}$ American men; WF=white women; $\mathrm{AAW}=\mathrm{African}$ American women. 
Table 3 Risks of stomach cancer by probability and intensity of exposure to asbestos, inorganic dust, metal dust, lead, nitrosamines, nitrogen oxides, PAHs, sulphuric acid, and fertilisers (white men)

\begin{tabular}{|c|c|c|c|c|c|c|c|c|c|}
\hline \multirow[b]{2}{*}{ Intensity of exposure } & \multicolumn{9}{|c|}{ Probability of exposure (n OR $(95 \% \mathrm{CI})$ ) } \\
\hline & \multicolumn{2}{|c|}{ All exposed } & \multicolumn{2}{|l|}{ Low } & \multicolumn{2}{|l|}{ Medium } & \multicolumn{2}{|l|}{ High } & $\begin{array}{l}\text { Test for } \\
\text { trend }\end{array}$ \\
\hline \multicolumn{10}{|l|}{ Inorganic dust: } \\
\hline All levels & 8904 & $1.07(1.03$ to 1.11$)$ & 1361 & $0.98(0.92$ to 1.05$)$ & 2666 & $1.11(1.05$ to 1.17$)$ & 4877 & $1.08(1.03$ to 1.13$)$ & $\mathrm{p}<0.01$ \\
\hline None & 11974 & 1.0 & 11974 & 1.0 & 11974 & 1.0 & 11974 & 1.0 & \\
\hline Low & 4635 & $1.05(1.0$ to 1.10$)$ & 971 & $0.97(0.90$ to 1.06$)$ & 1124 & $1.09(1.0$ to 1.18$)$ & 2540 & $1.08(1.01$ to 1.16$)$ & $\mathrm{p}<0.01$ \\
\hline Medium & 3002 & $1.07(1.01$ to 1.12$)$ & 302 & $1.04(0.91$ to 1.20$)$ & 1125 & $1.13(1.04$ to 1.22$)$ & 1575 & $1.03(1.0$ to 1.10$)$ & NS \\
\hline High & 1267 & $1.13(1.05$ to 1.21$)$ & 88 & $0.94(0.73$ to 1.22$)$ & 417 & $1.10(0.97$ to 1.25$)$ & 762 & $1.18(1.08$ to 1.30$)$ & $\mathrm{p}<0.01$ \\
\hline $\begin{array}{l}\mathrm{p} \text { Value test for } \\
\text { trend }\end{array}$ & $<0.01$ & & NS & & $<0.01$ & & $<0.01$ & & \\
\hline $\begin{array}{l}\text { Metals: } \\
\text { All levels }\end{array}$ & 4306 & 1.05 (1.0 to 1.09$)$ & 662 & $1.05(0.96$ to 1.16$)$ & 2142 & $1.04(0.98$ to 1.10$)$ & 1502 & $1.06(0.99$ to 1.13$)$ & $\mathrm{p}=\mathrm{NS}$ \\
\hline None & $\begin{array}{l}16572 \\
1.0\end{array}$ & & $\begin{array}{l}16572 \\
1.0\end{array}$ & & 16572 & 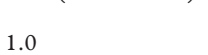 & 16572 & 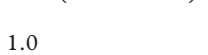 & \\
\hline Low & 1256 & $1.02(0.95$ to 1.09$)$ & 359 & $1.06(0.93$ to 1.21$)$ & 683 & $1.0(0.91$ to 1.10$)$ & 214 & $1.01(0.86$ to 1.20$)$ & $\mathrm{p}=\mathrm{NS}$ \\
\hline Medium & 1509 & $1.04(0.97$ to 1.11$)$ & 268 & $1.06(0.91$ to 1.23$)$ & 857 & $1.02(0.94$ to 1.11$)$ & 384 & $1.06(0.94$ to 1.21$)$ & $\mathrm{p}=\mathrm{NS}$ \\
\hline High & 1541 & $1.09(1.02$ to 1.16$)$ & 35 & $1.01(0.67$ to 1.51$)$ & 602 & $1.12(1.01$ to 1.24$)$ & 904 & $1.07(0.99$ to 1.17$)$ & $\mathrm{p}<0.05$ \\
\hline Test for trend & 0.01 & & NS & & 0.05 & & NS & & \\
\hline \multicolumn{10}{|l|}{ Nitrosamines: } \\
\hline All exposed & 4400 & $1.06(1.01$ to 1.11$)$ & 792 & $1.01(0.93$ to 1.10$)$ & 2760 & $1.08(1.02$ to 1.14$)$ & 848 & $1.05(0.97$ to 1.15$)$ & $\mathrm{p}<0.05$ \\
\hline None & 16478 & 1.0 & 16478 & 1.0 & 16478 & 1.0 & 16478 & 1.0 & \\
\hline Low & 433 & $0.99(0.88$ to 1.12$)$ & 201 & $0.94(0.79$ to 1.11$)$ & 169 & $1.05(0.87$ to 1.27$)$ & 63 & $1.06(0.78$ to 1.45$)$ & $\mathrm{p}=\mathrm{NS}$ \\
\hline Medium & 3474 & $1.06(1.01$ to 1.11$)$ & 487 & $1.01(0.90$ to 1.13$)$ & 2313 & $1.07(1.01$ to 1.14$)$ & 674 & $1.04(0.94$ to 1.14$)$ & $\mathrm{p}<0.05$ \\
\hline High & 493 & $1.16(1.03$ to 1.30$)$ & 104 & $1.21(0.95$ to 1.54$)$ & 278 & $1.16(1.0$ to 1.35$)$ & 111 & $1.12(0.89$ to 1.41$)$ & $\mathrm{p}=\mathrm{NS}$ \\
\hline $\begin{array}{l}\mathrm{p} \text { Value test for } \\
\text { trend }\end{array}$ & $<0.01$ & & NS & & $<0.01$ & & NS & & \\
\hline \multicolumn{10}{|l|}{ Sulphuric acid: } \\
\hline All levels & 5650 & $1.01(0.97$ to 1.05$)$ & 4531 & $1.0(0.96$ to 1.04$)$ & 675 & $1.12(1.01$ to 1.23$)$ & 444 & $0.96(0.85$ to 1.08$)$ & $\mathrm{p}=\mathrm{NS}$ \\
\hline None & 15228 & 1.0 & 15228 & 1.0 & 15228 & 1.0 & 15228 & 1.0 & \\
\hline Low & 4113 & $0.99(0.95$ to 1.03$)$ & 3624 & $0.99(0.95$ to 1.04$)$ & 144 & $1.13(0.92$ to 1.39$)$ & 345 & $0.91(0.80$ to 1.04$)$ & $\mathrm{p}=\mathrm{NS}$ \\
\hline Medium & 1274 & $1.03(0.96$ to 1.11$)$ & 845 & $1.04(0.95$ to 1.13$)$ & 408 & $1.05(0.93$ to 1.19$)$ & 21 & $0.79(0.48$ to 1.30$)$ & $\mathrm{p}=\mathrm{NS}$ \\
\hline High & 263 & $1.23(1.05$ to 1.44$)$ & 62 & $0.93(0.68$ to 1.26$)$ & 123 & $1.42(1.12$ to 1.79$)$ & 78 & $1.29(0.97$ to 1.72$)$ & $\mathrm{p}<0.01$ \\
\hline $\begin{array}{l}\mathrm{p} \text { Value test for } \\
\text { trend }\end{array}$ & 0.01 & & NS & & $<0.05$ & & NS & & \\
\hline
\end{tabular}

$\mathrm{n}=$ Number of exposed cases.

distribution with a single degree of freedom, and it probes specifically linear trends in log relative risk with increasing exposure. ${ }^{12} \mathrm{p}$ Values were two tailed.

\section{Results}

Mean age at death from stomach cancer was lower among men than among women and among African Americans than white people (African American men: 67.3 (SD 13.0); African American women: 71.4 (SD 14.6); white men: 69.4 (SD 12.3); white women: 74.2 (SD 12.8)). Compared with controls, cases were more often married in all four study groups, and they defined their ethnic origin (mainly European, or Hispanic) twice as often as controls among white men and white women. Other variables - such as metropolitan residence and socioeconomic status-did not show a consistent frequency distribution by case-control across the four study groups (not shown in the tables).

Risks by probability of exposure to $12 \mathrm{occu}-$ pational risk factors combining all levels of exposure are shown in table 1 . None of the investigated exposures showed an unequivocal trend in all study groups. Only inorganic dust

Table 4 ORs (95\% CI) for stomach cancer associated with any exposure to inorganic dust, metals, nitrosamines, and sulphuric acid adjusted for all the other exposures and by marital and socioeconomic status, and metropolitan residence

\begin{tabular}{lll}
\hline Exposure & OR & $95 \%$ CI \\
\hline Inorganic dust & 1.05 & 1.0 to 1.10 \\
Metals & 1.01 & 0.96 to 1.07 \\
Nitrosamines & 1.04 & 0.99 to 1.09 \\
Sulphuric acid & 0.99 & 0.95 to 1.03 \\
\hline
\end{tabular}

and nitrosamines were associated with ORs $>1.0$ for the high probability of exposure category in all four study groups. Two of the four risks associated with high probability of exposure to inorganic dust were significant and another was of borderline significance. Although absolute increases in risk were small, trends for probability of exposure to inorganic dust were significant among white men, white women, and African American men, and for exposure to nitrosamine among white men and white women.

Table 2 shows risks by intensity of exposure to the same 12 occupational risk factors. High intensity exposure to the risk factors was rare among women. However, a significant positive trend in at least one study group was found for inorganic dust, metals, nitrosamines, nitrogen oxides, and sulphuric acid. Again, although absolute risk increases were small, the significant trends by intensity of exposure to inorganic dust and nitrosamines among white men replicated similar findings that used probability of exposure.

Patterns of increasing risk of stomach cancer by probability within intensity category and vice versa were explored for inorganic dust, metals, nitrosamines, and sulphuric acid (table 3). Although excess risks were quite small, trends by probability of exposure to inorganic dust were significant in low and high categories of intensity, and trends by intensity of exposure were significant for subjects classified in the medium and high probability of exposure. Results were less consistent for metals, nitrosamines, and sulphuric acid. No such pattern was found for exposure to the other workplace 
Table 5 Risks of stomach cancer by probability and intensity of exposure to inorganic dust among subjects unexposed to metals and nitrosamines (white men)

\begin{tabular}{|c|c|c|c|c|c|c|c|}
\hline \multirow[b]{2}{*}{ Intensity of exposure } & \multicolumn{7}{|c|}{ Probability of exposure (n OR $(95 \% C I))$} \\
\hline & Low & & Medium & & High & & $\begin{array}{l}p \text { Value } \\
\text { test for } \\
\text { trend }\end{array}$ \\
\hline \multicolumn{8}{|l|}{ Inorganic dust: } \\
\hline Unexposed & 10955 & 1.0 & 10955 & 1.0 & 10955 & 1.0 & \\
\hline Low & 701 & 0.93 (0.84 to 1.02$)$ & 705 & $1.23(1.10$ to 1.38$)$ & 180 & $0.96(0.80$ to 1.15$)$ & NS \\
\hline Medium & 59 & $0.94(0.69$ to 1.28$)$ & 293 & $1.13(0.97$ to 1.30$)$ & 680 & $1.01(0.91$ to 1.12$)$ & NS \\
\hline High & 13 & $1.14(0.58$ to 2.24$)$ & 59 & $1.10(0.80$ to 1.51$)$ & 359 & $1.20(1.04$ to 1.38$)$ & $<0.01$ \\
\hline $\mathrm{p}$ Value test for trend & NS & & NS & & $<0.05$ & & \\
\hline
\end{tabular}

hazards considered in this study. To see whether reciprocal confounding was responsible for some of the observed associations, we combined all categories of exposure and fitted a model with the basic variables plus exposure to inorganic dust, metals, nitrosamines, and sulphuric acid to reciprocally adjust the respective risk estimates. As reported in table 4, this analysis resulted in a very modest increase in risk of stomach cancer for exposure to inorganic dust and to nitrosamines, but no excess risk was associated with ever exposure to metals and sulphuric acid.

Cross tabulation of probability and intensity of exposure to inorganic dust among workers unexposed to metals and to nitrosamines showed significantly positive trends by probability in the high intensity category and by intensity in the high probability category (table 5). The analysis of such a risk pattern among subjects with isolated exposure to metals or to nitrosamines did not provide interpretable results due to small numbers and empty cells.

Among white men, the most numerous occupation contributing to the excess risk associated with high probability and high intensity of exposure to inorganic dust was mining machine operators represented by $1.34 \%$ cases and $1.25 \%$ controls. Other less numerous contributing occupations were: plasterers $(0.05 \%$ cases and $0.04 \%$ controls $)$, concrete and terrazzo finishers $(0.12 \%$ cases and $0.07 \%$ controls), mining occupations not elsewhere classified $(0.10 \%$ cases and $0.09 \%$ controls), excavating and loading machine operators $(0.04 \%$ cases and $0.03 \%$ controls), and crushing and grinding machine operators (two cases and no controls). In the same study group, the most represented industry contributing to the excess risk of stomach cancer in the high probability and high intensity of exposure to inorganic dust was mining and quarrying $(1.49 \%$ cases and $1.35 \%$ controls). Coal mining, metal mining, and non-metallic mining and quarrying contributed equally to the modest excess risk. Other contributing industries were: construction $(0.21 \%$ cases and $0.13 \%$ controls), and structural clay products (three cases and three controls).

\section{Discussion}

In this large case-control study based on death certificates from 24 states from the United States we found a modest association of risk of stomach cancer with occupational exposure to inorganic dust. Although the increase in risk was tiny, increasing trends were calculated by probability and intensity of exposure overall and by cross classification of the two exposure metrics. Other suspected risk factors for gastric cancer did not show the same association or showed a even weaker association after adjustment for exposure to inorganic dust. Our data do not provide information about whether ingestion of generic inorganic dust or specific dust components play a part in gastric carcinogenesis. Therefore, one possible explanation for our findings is that exposure to inorganic dust may have behaved as a partial surrogate for exposure to other unknown risk factors. Alternatively, dusty workplace environments could play a non-specific role in gastric carcinogenesis. If the association were confirmed with exposure to generic inorganic dust, a plausible explanation would be that physical properties of dust might be important, by causing local irritation or absorbing gastric carcinogens on its surface and delivering them to the target cells in the gastric mucosa. Such a mechanism was experimentally proved long ago in lung carcinogenesis. ${ }^{4}$

Previous case-control studies have reported an association between occupational exposure to dust and stomach cancer,,$^{513-15}$ not explained by ethnicity ${ }^{13}$ or diet. ${ }^{5}$ Results were less consistent for a role of specific dusts. A case-control study based on the Los Angeles County cancer registry found the greatest increase in risk of cancer of the antrum or pylorus for exposure to mineral dust. ${ }^{14}$ The association was also found in an Italian multicentre case-control study of 640 hystologically confirmed male cases of stomach cancer, ${ }^{5}$ although no attempt was made to investigate subsites in more detail. In a large multicancer site, multifactor case-control study in Montreal, Canada, silica was the only inorganic dust, ${ }^{15}$ and wood the only organic dust ${ }^{13}$ to show a positive association with stomach cancer. Disentangling exposure to silica from other inorganic dust would require additional information on workplaces and possibly industrial hygiene measurements, which was not the case in the present study. On the other hand, we did not find an association with wood dust, the only organic dust we tested, and trends associated with exposure to metals (which included dust and fumes) were less consistent than with the more generic category of inorganic dust (including also metal dust). Exposure to lead was not associated with a risk of stomach cancer, and adjustment for exposure to inorganic dust weakened the positive association found with nitrosamines. Cross 
tabulation of probability and intensity of isolated exposure to nitrosamines did not provide further clues, because of small numbers and empty cells. Endogenous synthesis of nitrosamines from dietary precursors was suggested as the crucial event in gastric carcinogenesis. ${ }^{2}$ Exposure to nitrosamine precursors or to preformed nitrosamines in the work environment was also suggested as a possible explanation for the repeatedly found increase in risk of gastric cancer in industries where such exposures may occur. ${ }^{1}$ Further study including monitoring of exposure to nitrosamines in the work environment and in biological fluids of exposed workers are warranted.

Occupational exposures in agriculture, such as to herbicides, other pesticides, and fertilisers, were not associated with a risk of gastric cancer in this study. A review of cancer among farmers suggested a possible increase in risk of stomach cancer. ${ }^{16}$ The epidemiological evidence for this seems to be conflicting, ${ }^{1}$ and confounding by rural residence was suggested as a possible explanation. ${ }^{5}$

Limitations in this study are mainly related to the poor occupational information that may be extracted from death certificates and the insufficient specificity of the coding system. Use of the most prevalent occupation and industry in the working history of each person as reported in the death certificate may result in important loss of information on exposures experienced in other jobs, mainly among short term workers who usually experience the highest workplace exposures. ${ }^{17}$ Besides, the three digit census code of occupations and industries may incorporate very heterogeneous workplace conditions within the same code, which prevents a reliable classification of exposure. Although this characteristic was considered in classifying occupations and industries by probability of exposure, a substantial amount of non-differential misclassification could have affected our results, which could have lowered the association between stomach cancer and occupational exposure to inorganic dust. ${ }^{18}$

Among possible confounders, ethnic origin, marital status, and socioeconomic status were included in the logistic regression model. As rural residence is another important confounder in occupational studies of stomach cancer, ${ }^{5}$ but an urban or rural characterisation of residence was not available from the death certificates, we used metropolitan versus nonmetropolitan residence as a surrogate. Region of residence was controlled for by matching cases and controls. The analysis was conducted separately by race and sex groups. As controlling for diet was not possible, residual confounding may have biased our findings in cases of important differences in dietary habits associated with the occupational exposures considered in this study.

Gastric cancer risk is reportedly correlated with low educational level and low socioeconomic status. ${ }^{1920}$ Therefore, risks associated with exposures typical of occupations classified in the lower socioeconomic groups, such as inorganic dust, might have been affected as well. Low socioeconomic status was not associated with stomach cancer risk in our study, which was conducted using a death certificate data-base. This source of information is not suitable to evaluate the association between low socioeconomic status and mortality from specific diseases, as bias can result from a more accurate definition of the cause of death and a lower mortality from all causes among the wealthier socioeconomic groups. As a consequence, in our study, when socioeconomic status was not included as a covariate in the logistic regression model to adjust risk estimates, risks associated with intensity and probability of exposure to inorganic dust were 1.0 or very close to unity, and no positive trend was found (not shown in the tables). On the other hand, risk associated with high probability of exposure to inorganic dust was increased in three out of four socioeconomic groups comprising exposed cases (lowest socioeconomic status: 1.12; second lowest socioeconomic status: 1.11 ; medium socioeconomic status: 0.89 ; medium to high socioeconomic status: no cases; highest socioeconomic status: 1.08), although linear increases with probability of exposure were found only in the two lowest socioeconomic groups. Odds ratios for high intensity exposure to inorganic dust were increased in three socioeconomic groups (no cases and no controls were classified in this cell among the medium to high and the highest socioeconomic status category), and linear increases in risk with intensity of exposure were found in the second lowest and medium socioeconomic status (not shown in the tables). Therefore, low socioeconomic status was not an explanation for the modest increase in risk of stomach cancer associated with exposure to inorganic dust found in our study.

In conclusion, our results confirm previous reports of an association between occupational exposure to inorganic dust and risk of stomach cancer. Further research is warranted to explore mechanisms and dose-response relations possibly with measurements of environmental dust.

1 Cocco P, Ward M, Buiatti E. Occupational risk factors for stomach cancer: an overview. Epidemiol Rev 1996;18:218 34.

2 Correa P. Human gastric carcinogenesis: a multistep and multifactorial process (First American Cancer Society Award Lecture on Cancer Epidemiology and Prevention). Award Lecture on Cancer Epic

3 La Vecchia C, Negri E, D'Avanzo B, et al. Food temperature and gastric cancer. Int $\mathcal{F}$ Cancer 1990;46:432-4.

4 Saffiotti U, Cefis F, Kolb LH. A method for the experimental induction of bronchogenic carcinoma. Cancer Res 1968; 28:104-24.

5 Cocco PL, Palli D, Buiatti E, et al. Occupational exposures as risk factors for gastric cancer. Cancer Causes Control 1994;5:241-8.

6 Bureau of the Census. Alphabetical index of industries and occupations. Washington, DC, US: Department of Commerce, 1982. (PHC80-R3.)

7 Burnett CA, Maurer J, Dosemeci M. Mortality by occupation, industry, and cause of death. Cincinnati, OH: US Department of Health and Human Services, National Institute for Occupational Safety and Health, 1997. (DHHS NIOSH Publ No 97-114)

8 Parmeggiani L, ed. Encyclopedia of occupational health and safety, 3rd ed. Geneva, Switzerland: International Labour Office, 1985.

9 Zenz C. Occupational medicine. Principles and practical applications, 2nd ed. Chicago, IL: Yearbook Medical Publishers, 1988 
10 Gomez MR, Cocco PL, Dosemeci M, et al. Occupational exposure to chlorinated aliphatic hydrocarbons and brain cancer risk: job-exposure matrix. Am f Ind Med 1994;26 $171-83$

11 Green LW. Manual for scoring socioeconomic status for research on health behavior. Public Health Rep 1970;85: 815-27.

12 Breslow NE, Day NE. Statistical methods in cancer research. Vol I. The analysis of case-control studies. Lyon, France: International Agency for Research on Cancer, 1980 (IARC Sci Publ No 32 .)

13 Siemiatycki J, Richardson L, Gerin M, et al. Associations between several sites of cancer and nine organic dusts: results from a hypothesis-generating case-control study in Montreal, 1979-83. Am f Epidemiol 1986;123:235-49.

14 Wright WE, Bernstein L, Peters JM, et al. Adenocarcinoma of the stomach and exposure to occupational dust. Am $\mathcal{F}$ Epidemiol 1988;128:64-73.
15 Siemiatycki J, Dewar R, Lakhani R, et al. Cancer risks associated with 10 inorganic dusts: results from a case-control study in Montreal. Am F Ind Med 1989;16:547-67.

16 Blair A, Zham SH, Pearce NE, et al. Clues to cancer etiology from studies among farmers. Scand $\mathcal{f}$ Work Environ Health 1992;18:209-15.

17 Gardner MJ. Considerations in the choice of expected numbers for appropriate comparisons in occupational cohort studies. Med Lav 1986;77:23-47.

18 Rothman KJ. Modern epidemiology. Boston, MA: Little Brown, 1986

19 Pearce NE, Howard JK. Occupation, social class and male cancer mortality in New Zealand, 1974-8. Int $\mathcal{f}$ Epidemiol 1986;15:456-62.

20 Buiatti E, Palli D, DeCarli A, et al. A case-control study of gastric cancer and diet in Italy. Int f Cancer 1989;44:611- 